\title{
A técnica da coordenação modular como ferramenta diretiva de projeto
}

\author{
The modular coordination technique as a guiding design \\ tool
}

\author{
Aline da Silva Ramos Barboza \\ Marcelle Maria Correia Pais Silva \\ Larissa Lara da Silva \\ Josival Corrêa de Araújo Júnior
}

\section{Resumo}

Aline da Silva Ramos Barboza Departamento de Engenharia Estrutural, Centro de Tecnologia Universidade Federal de Alagoas Av. Lourival de Melo Mota, s/n, Cidade Universitária Maceió - AL - Brasil CEP 57072-970 Tel.: (82) 3214-1296 E-mail: aline@lccv.ufal.br

Marcelle Maria Correia Pais

Silva

Superintendência de Infraestrutura Universidade Federal de Alagoas Av. Lourival de Melo Mota, $\mathrm{s} / \mathrm{n}$, Cidade Universitária Maceió - AL - Brasil CEP 57072-970 Tel.: (82) 3214-1510 E-mail: marcellepais@yahoo.com.br

Larissa Lara da Silva Faculdade de Arquitetura Universidade Federal de Alagoas Campus A. C. Simões, BR 104, Norte, Km 97, Cidade Universitária Maceio - AL - Brasil CEP 57072-970 Tel.: (82) 9158-8483 E-mail: larissapops@gmail.com

Josival Corrêa de Araújo Júnior Faculdade de Arquitetura Universidade Federal de Alagoas Tel.:(82) 8832-1674 E-mail: josival_junior@hotmail.com

Recebido em 26/10/10 Aceito em 30/05/11

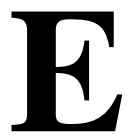

m diversos processos e sistemas construtivos atualmente empregados na habitação de interesse social, existem muitos problemas relacionados à falta de coordenação modular e baixa conectividade entre os componentes envolvidos que resultam na incidência de perdas e baixa produtividade. O presente trabalho objetiva a utilização da técnica da coordenação modular e da conectividade à produção de alvenaria de blocos cerâmicos e de concreto, com vistas à melhoria de desempenho deste processo construtivo. Para o desenvolvimento do trabalho, foi realizado um levantamento dimensional de componentes da alvenaria nas fábricas locais de blocos de vedação (cerâmico e concreto) e de blocos, esquadrias e revestimentos cerâmicos normalmente utilizados nas principais lojas de materiais de construção de Maceió, AL. Os dados coletados foram analisados estatisticamente com o software SPSS (Statistical Package for the Social Sciences). Com base nesta análise, foi proposta a modulação de um painel de alvenaria de blocos considerando a conectividade entre os componentes de vedação, que é normalmente utilizada na prática construtiva da região, e os componentes de maior representatividade no comércio de Maceió. Esse painel pode ser aplicado para o projeto de sistemas de vedação em alvenaria de blocos com ou sem aberturas, melhorando a produtividade e reduzindo o desperdício no processo de execução.

Palavras-chave: Coordenação modular. Conectividade. Sistemas construtivos. Projeto arquitetônico. Empreendimentos habitacionais de interesse social.

\section{Abstract}

In several building processes and systems currently used in social housing projects, there are many problems related to the lack of modular coordination and low connectivity between components, which result in the high incidence of waste and low productivity. This study aims to use the modular coordination and connectivity techniques in masonry with the aim of improving the performance of this construction process. The study involved a survey of the dimensions of masonry components in local manufacturers of ceramic and concrete blocks, and of blocks, window-and door-frames, and ceramic tiles in the main building material distributors from Maceio, state of Alagoas. The data collected were statistically analyzed using the SPSS (Statistical Package for the Social Sciences) software. Based on that analysis, the modulation of a block masonry panel was defined considering the connectivity between the components normally used, and the components most frequently offered by suppliers in the region. This panel can be applied in the design of block masonry partitions, with or without openings, improving productivity and reducing waste in the construction process.

Keywords: Modular coordination. Connectivity. Building systems. Architectural design. Social housing projects. 


\section{Introdução}

Nos diversos processos e sistemas construtivos atualmente empregados nas edificações, vem sendo verificado um grande quantitativo de desperdícios e perda de produtividade, devido à baixa conectividade entre os componentes envolvidos nos sistemas. Tal constatação influencia de forma direta o bom andamento e a qualidade da obra. Nesse contexto, a percepção da obra como um conjunto de componentes e sistemas articulados, e não apenas um canteiro de serviços de transformação de materiais básicos, vem simplificar a gestão e possibilitar novas formas de produção, com maior produtividade e qualidade.

Com a necessidade de reconstrução das cidades, registrada no período pós-guerra, a coordenação modular veio a se consolidar principalmente na Europa, por consistir em um sistema capaz de racionalizar e ordenar a fabricação de qualquer componente, desde o projeto até o produto final. Entendida como uma ordenadora de espaços, a coordenação modular permite relacionar as medidas de projeto com as medidas da produção industrial, sem abandonar as questões da composição geométrica e de proporções. Por meio dela, criam-se critérios para a definição de dimensões e a explicitação da conectividade entre os componentes. A ordenação e a racionalização se efetivam por meio de uma medida de referência denominada módulo, o qual será respeitado em todos os espaços e componentes do projeto (BARBOZA et al., 2008; GREVEN; BALDAUF, 2007).

A metodologia construtiva, associada às dimensões explícitas dos componentes, evidencia a coordenação modular como ferramenta diretiva de projeto e execução de uma obra, visando à economia e à qualidade, sem que esta venha a perder sua identidade e seu caráter diferencial.

O presente trabalho objetiva demonstrar a aplicação da técnica da coordenação modular e conectividade a partir de um diagnóstico dos principais componentes de sistemas de vedação comercializados e aplicados na cidade de Maceió, melhorando assim a produtividade e reduzindo os desperdícios em obras de cunho social.

\section{Métodos de pesquisa}

Inicialmente, realizou-se um levantamento dimensional de blocos, esquadrias e revestimentos cerâmicos para alvenaria de vedação, nos principais fabricantes e fornecedores de MaceióAL, e em seguida executou-se a tabulação dos dados coletados utilizando o software SPSS. Com esses dados, verificou-se uma grande variabilidade dimensional. Após a elaboração de painéis de alvenaria de blocos ajustados à coordenação modular, procurou-se adequar projetos locais para a construção de habitações de interesse social, em duas cidades objetos de estudo e um centro social urbano, demonstrando, assim, a aplicabilidade de tal metodologia construtiva em qualquer tipo de obra, incluindo os aspectos de repetição definidos por Nissen (1972). Com a variabilidade dimensional encontrada nos componentes de vedação e a prática construtiva adotada na região, os ajustes necessários a um sistema coordenado modularmente exigiram a proposição de elementos complementares (WINTER, 2005), como vergas e blocos não existentes no mercado.

\section{Levantamento dimensional}

O levantamento dimensional dos principais componentes da alvenaria de vedação aplicados na cidade de Maceió foi obtido por meio de questionários aplicados aos principais fornecedores de materiais para a construção civil (esquadrias, blocos cerâmico e de concreto e revestimentos cerâmicos), e aos consumidores de materiais de construção (construtoras). As construtoras selecionadas para aplicação dos questionários são certificadas com sistema de gestão de acordo com a ISO 9001 (ABNT, 2008).

Com base nos questionários aplicados junto às construtoras selecionadas, percebeu-se que todas elas utilizam blocos cerâmicos, revestimentos cerâmicos e esquadrias em $100 \%$ de suas obras, poucas delas começaram a usar o bloco de concreto (como vedação) e o de gesso para as alvenarias internas.

Atualmente, existem 23 empresas cerâmicas associadas ao Sindicato das Indústrias Cerâmicas do Estado de Alagoas, das quais cinco estão em processo de certificação. Foram visitadas seis empresas cerâmicas, para aplicação de questionários e coleta de amostras de blocos cerâmicos. Apenas quatro empresas cerâmicas abastecem as construtoras de Maceió com os blocos cerâmicos, sendo três do estado de Alagoas e uma do estado do Rio Grande do Norte. Isso se deve ao porte das empresas produtoras, a maioria delas com mercado localizado apenas no entorno, e a variabilidade na qualidade do bloco cerâmico produzido no estado.

Quanto aos revestimentos cerâmicos, aplicaram-se questionários e coletaram-se amostras para estudos. Cerca de $80 \%$ das construtoras utilizam entre $50 \%$ e $99 \%$ de revestimentos cerâmicos nas 
fachadas e usam em mais de $50 \%$ das obras esse mesmo material nas paredes de banheiros e cozinhas. Não trabalham sempre com o mesmo fornecedor, pois este varia de acordo com o padrão da obra.

As dimensões das peças cerâmicas apresentam variação tanto em relação ao mesmo fornecedor quanto de um para outro.

O estudo realizado com esquadrias foi realizado com a aplicação de questionário, coleta de dados e medição desses componentes in loco, para maior precisão dos dados coletados. Todas as portas externas e internas, normalmente utilizadas, são de madeira, e as janelas, de alumínio. Observou-se que a maioria trabalha sempre com o mesmo fornecedor em mais de $50 \%$ das obras, tanto para as portas quanto para as janelas.

\section{Estudos de caso}

\section{Habitação de interesse social}

Para a aplicação da técnica da coordenação modular como diretiva de projeto, considerando os componentes obtidos a partir do levantamento dimensional, foram utilizados dois projetos de habitação de interesse social a serem executados em duas cidades do interior do estado de Alagoas. Todas elas seriam edificadas em terrenos dotados de infraestrutura, atendendo às orientações do Normativo do Programa Habitacional de Interesse Social - Ministério das Cidades - Ação de Apoio à Provisão Habitacional de Interesse Social. O programa de necessidades dessas habitações é composto de sala, dois quartos, BWC, cozinha e área de serviço.

\section{Caso 1}

As habitações possuem em seu projeto arquitetônico uma área de $44,10 \mathrm{~m}^{2}$. Sua alvenaria será executada em blocos de concreto com dimensões de 40x20x10 cm, de meia vez, onde suas juntas não ultrapassam $1,5 \mathrm{~cm}$.

\section{Caso 2}

Neste projeto, serão utilizados blocos cerâmicos com dimensões de 190x190x90 mm, bloco este fabricado pelas cerâmicas do estado.

\section{Centro Social Urbano}

A partir da experimentação das habitações de interesse social, a técnica da coordenação modular foi aplicada no projeto de um Centro Social Urbano, equipamento público comunitário que tem como principal meta atuar nas áreas mais periféricas das cidades, prestando serviços básicos para a comunidade na busca da qualificação do cidadão.

\section{Resultados e discussão}

Os dados colhidos nas principais construtoras, empresas cerâmicas e lojas de materiais de construção da cidade de Maceió para as dimensões referentes a componentes de vedação foram posteriormente tabulados no software Statistical Package for the Social Sciences (SPSS for Windows), possibilitando sua análise crítica através da produção de gráficos (Figuras 1 a 13) que apontam as principais dimensões dos componentes utilizados.

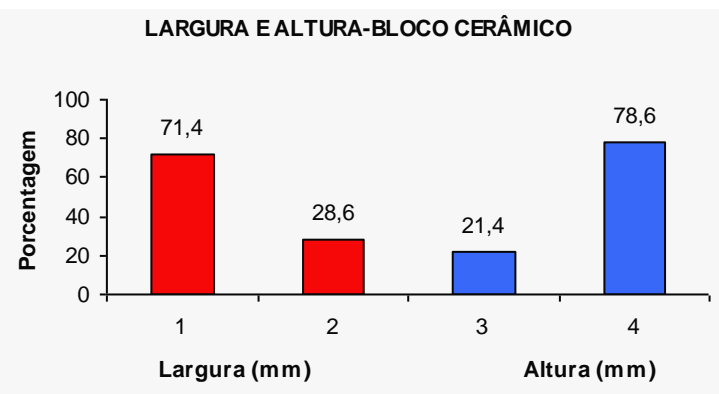

Figura 1 - Variabilidade da largura e altura dos blocos cerâmicos mais utilizados nas construtoras de Maceió - AL 


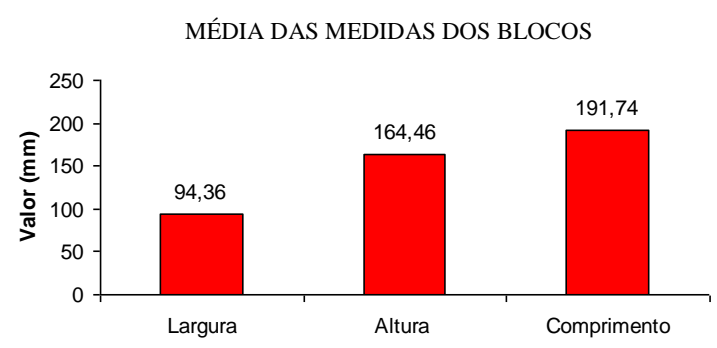

Figura 2 - Largura, altura e comprimento dos blocos cerâmicos mais utilizados nas construtoras de Maceió - AL

REVESTIMENTO CERÂMICO-COMPRIMENTO

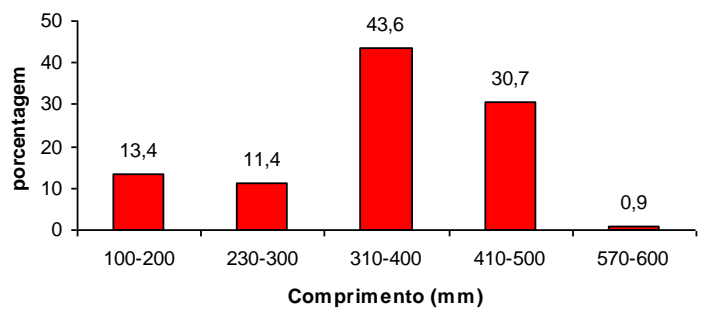

Figura 3 - Variação no comprimento dos revestimentos cerâmicos nos diversos fornecedores de Maceió - AL

REVESTIMENTO CERÂMICO-LARGURA

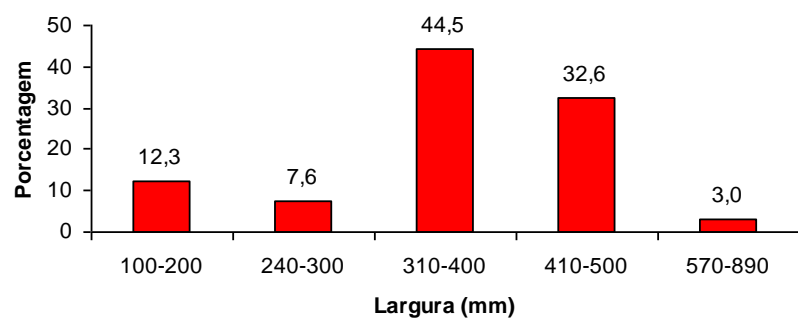

Figura 4 - Variação na largura dos revestimentos cerâmicos nos diversos fornecedores de Maceió - AL

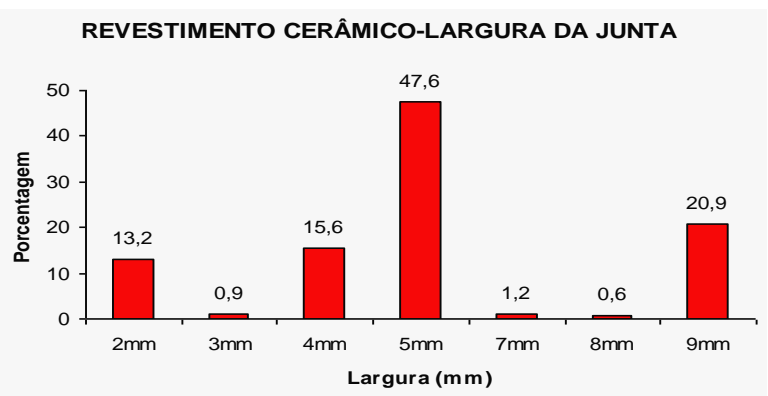

Figura 5 - Revestimento cerâmico - tamanho da junta proposta pelos fabricantes 
Largura da Folha da Porta (LFP)

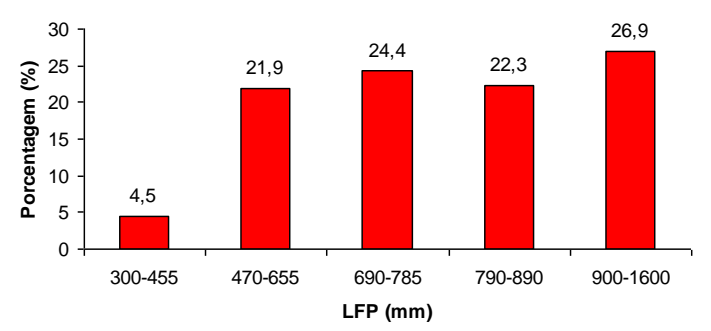

Figura 6 - Variação na dimensão da largura das folhas das portas nos diversos fornecedores de Maceió $\mathrm{AL}$

Largura Total da Porta (LTP)

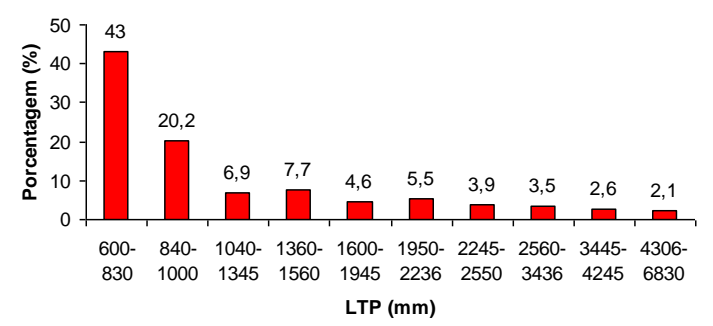

Figura 7 - Variação na dimensão da largura das portas nos diversos fornecedores de Maceió - AL

Altura da Folha da Porta (AFP)

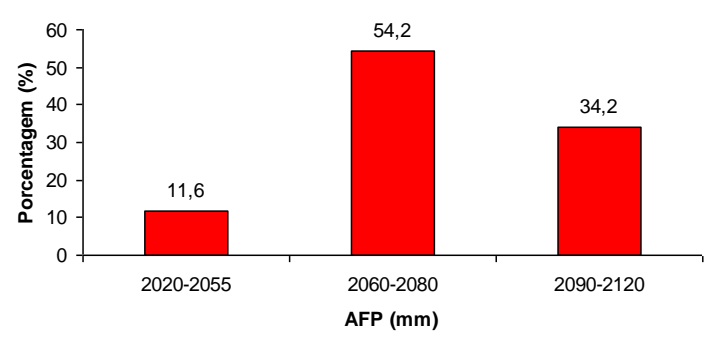

Figura 8 - Variação na dimensão da altura das folhas das portas nos diversos fornecedores de Maceió $\mathrm{AL}$

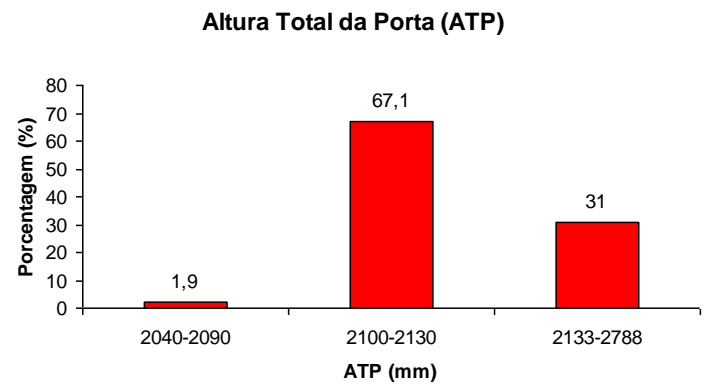

Figura 9 - Variação na dimensão da altura das portas nos diversos fornecedores de Maceió - AL 
Largura da folha da Janela (LFJ)

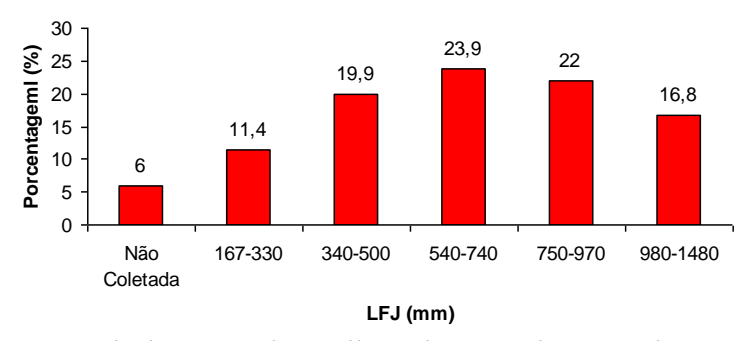

Figura 10 - Variação na dimensão da largura das folhas das janelas nos diversos fornecedores de Maceió - AL

Largura Total da Janela (LTJ)

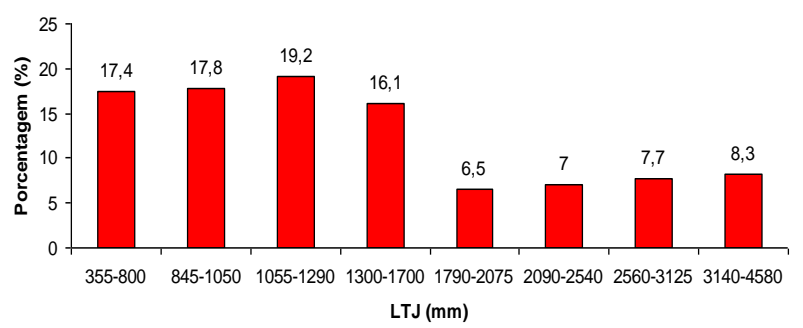

Figura 11 - Variação na dimensão da largura das janelas nos diversos fornecedores de Maceió - AL

Altura da Folha da Janela (AFJ)

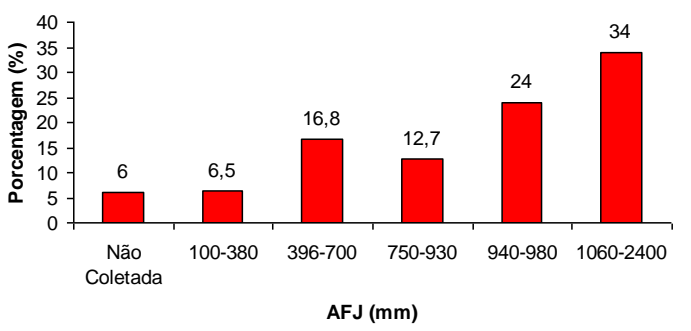

Figura 12 - Variação na dimensão da altura das folhas das portas nos diversos fornecedores de Maceió AL

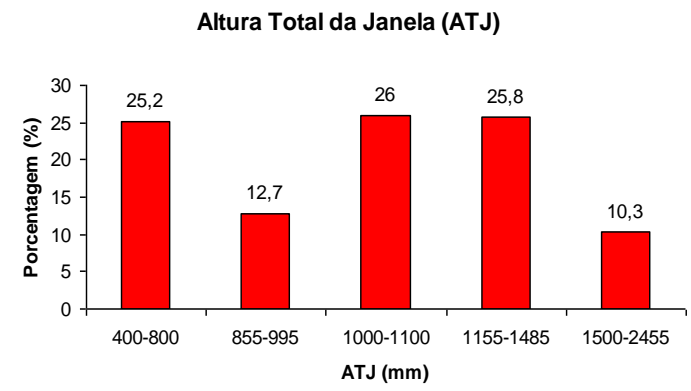

Figura 13 - Variação na dimensão da altura das portas nos diversos fornecedores de Maceió - AL

Com foco no objetivo do trabalho, de aplicar a técnica da coordenação modular considerando componentes normalmente comercializados na cidade, pela análise realizada através dos gráficos é perceptível a grande variedade de dimensões encontradas no mercado de Maceió, necessitando, assim, que o projeto se ajuste aos componentes que existem no mercado, limitando que este seja pensado já de acordo com as normas vigentes da coordenação modular. Por exemplo, na aplicação da técnica da coordenação modular no projeto da habitação de interesse social, Caso 1, algumas dimensões de projeto foram alteradas, resultando

102 Barboza, A. da S. R.; Silva, M. M. P.; Silva, L. L. da; Araújo Júnior, J. C. de 
em um aumento final da área de $44,10 \mathrm{~m}^{2}$ para $46,64 \mathrm{~m}^{2}$ (Figura 14).

Além das mudanças no projeto arquitetônico, para que o bloco de concreto considere a conectividade com a argamassa de assentamento incorporada pela prática construtiva da região, propõe-se a alteração das dimensões, 400×200×100 mm para 390x190x90 mm, com junta de $10 \mathrm{~mm}$. Essa mudança se faz necessária uma vez que o conjunto fica em desacordo com a modulação da alvenaria, que é de $3 \mathrm{M}$ × $2 \mathrm{M}$ em planimetria e altimetria respectivamente.

Como o uso do bloco padrão não é suficiente para se aplicar a coordenação modular na habitação, foi necessária a criação de uma família de blocos que corresponde a blocos que são equivalentes a $1 / 3 \mathrm{e}$ a 2/3 do bloco citado e, para as amarrações, a criação de blocos em L e em T (Figura 15), além do emprego dos componentes complementares, vergas acima dos vãos de portas e janelas e de componentes pré-moldados nos lugares das empenas, evitando, assim, o recorte dos blocos, que são constantes nessas regiões e onde a aplicação da malha modular é bastante dificultada.

Para a habitação de interesse social do estudo de caso 2 (Figura 16), a escolha do bloco cerâmico com as dimensões de 190x190x90 mm se dá por sua boa adequação ao sistema de coordenação modular, com malha modular de $2 \mathrm{M}$ x $2 \mathrm{M}$, em planimetria e altimetria, sendo $M=10 \mathrm{~cm}$ e junta de $10 \mathrm{~mm}$. Em todo o projeto será necessário, além do bloco em sua dimensão original, o meio-bloco, componente este com dimensões de 90x190x90 $\mathrm{mm}$, que não faz parte da linha de produção das cerâmicas do estado. Além dos blocos cerâmicos, exigem-se ainda os componentes complementares, que são as vergas e os elementos de empena que promovem a conexão entre a alvenaria e a coberta.

Os componentes de empena foram criados para buscar solucionar uma das áreas de maior conflito entre a forma atual de produção de habitações e os princípios da coordenação modular, como descrito por Habraken (1979). Nesse sentido, a proposta se concretiza mediante a pré-fabricação de peças com desenho que promove o intercâmbio entre a alvenaria e os elementos de coberta. Para os componentes de empena propostos, determinam-se as seguintes características:
(a) são pré-moldados leves;
(b) substituem blocos de alvenaria recortados, promovendo o ajuste modular altimétrico;

(c) respeitam a modulação da alvenaria; e

(d) não interrompem o ritmo da construção.

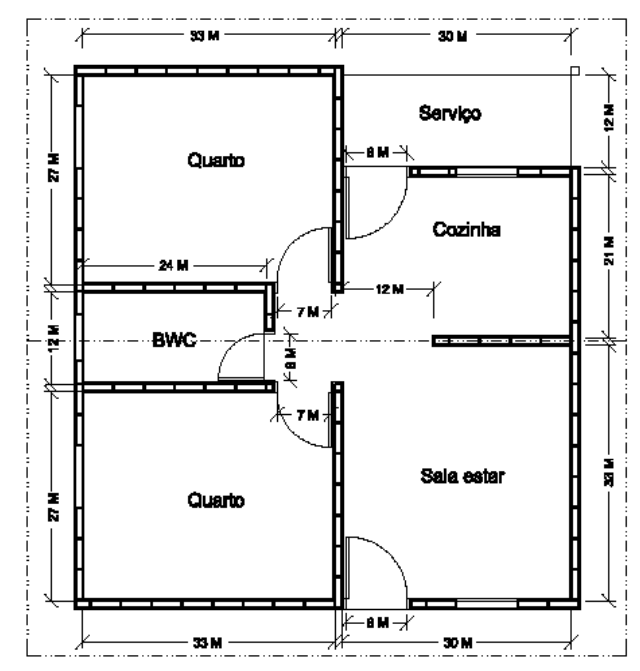

Figura 14 - Planta baixa da proposta da habitação do estudo de caso 1 usando a coordenação modular

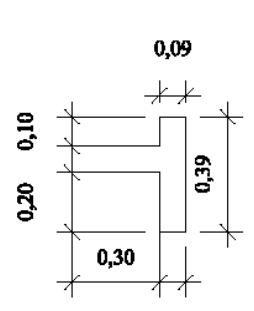

0,09

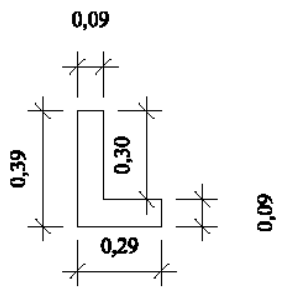

8

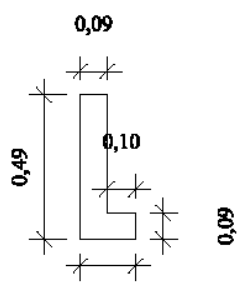

0,19

Figura 15 - Componentes da família de blocos em T e L 


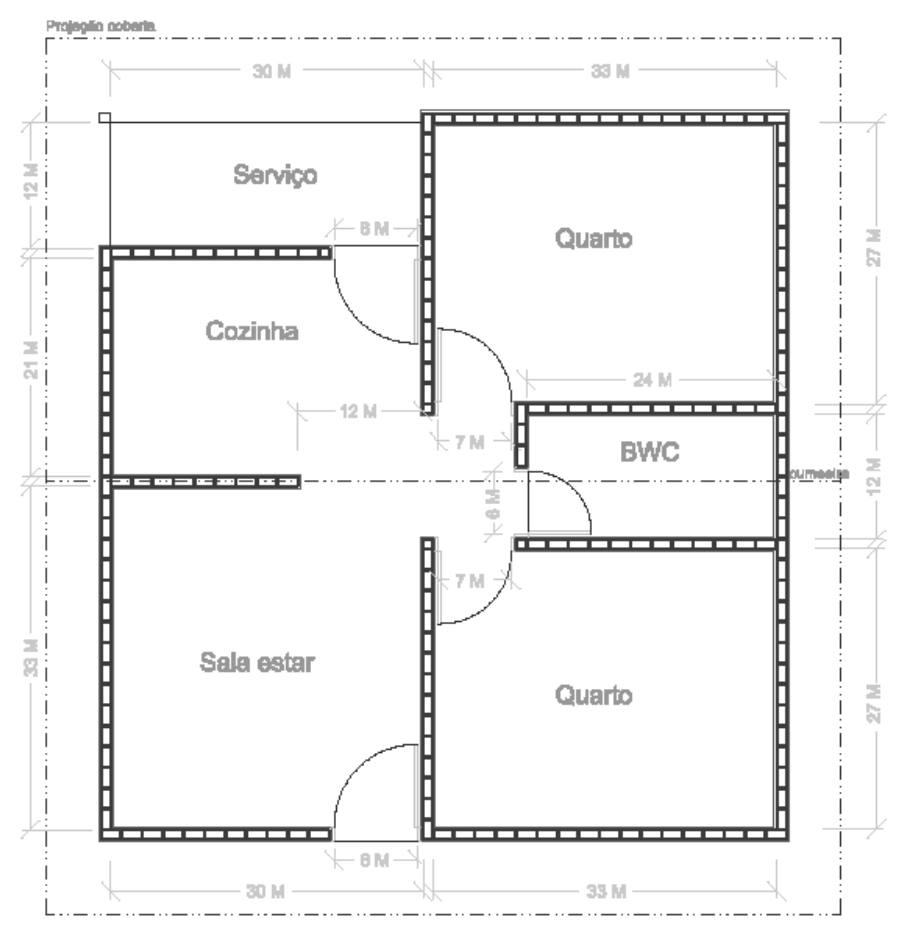

Figura 16 - Planta baixa de proposta da habitação para Viçosa-AL usando a coordenação modular

Portanto, esses componentes têm grande importância na produção de habitações ao contribuir com sua racionalização pro meio de ajustes dimensionais. Ao considerar o revestimento cerâmico de piso, propõe-se um que também está presente na pesquisa de mercado realizada em Maceió, que se configura com as dimensões de 295x295 mm com junta de $5 \mathrm{~mm}$, enquadrando-se, dessa forma, na malha modular de $3 \mathrm{M} \times 3 \mathrm{M}$.

$\mathrm{Na}$ proposta do Centro Social Urbano é possível identificar vários componentes utilizando a técnica da coordenação modular. O projeto é composto de três setores: administrativo, pedagógico e de lazer (Figuras 17 a 19). Nos referidos setores, pode-se observar uma alvenaria com malha modular de 4M $\mathrm{x} 4 \mathrm{M}$, tanto em sua planimetria como em sua altimetria, com blocos padrão e junta de $10 \mathrm{~mm}$ (Figuras 20 e 21). Para detalhamento da aplicação da técnica, considerou-se como exemplo o módulo da sala de aula, que possui dimensões de 7,25x7,25 $\mathrm{m}$. Observa-se que, para adequar os outros módulos à coordenação, basta aumentar ou diminuir 0,40 $\mathrm{m}$ de acordo com o uso do ambiente a ser projetado. Ainda, pode-se pensar na redução de custos criando uma malha para os revestimentos cerâmicos de 6M x 6M. Onde é possível empregar duas alternativas de dimensões, pode-se utilizar um revestimento cerâmico de $30 \times 30 \mathrm{~cm}$ ou um de 60x60 cm, usando a mesma lógica empregada na alvenaria, e os demais ambientes deverão aumentar ou diminuir 0,60 $\mathrm{m}$ em suas dimensões, de acordo com seu uso.

Para conseguir empregar a modulação de $6 \mathrm{M}$ x $6 \mathrm{M}$ é necessário que seja empregada uma junta de 2 $\mathrm{mm}$ e que se faça em todo o perímetro do ambiente uma moldura com $5 \mathrm{~mm}$, para, a partir desta, começar a assentar a cerâmica e então aplicar a junta de $2 \mathrm{~mm}$ entre uma cerâmica e outra (Figura 22). 


\section{Figura 17 - Setor administrativo}
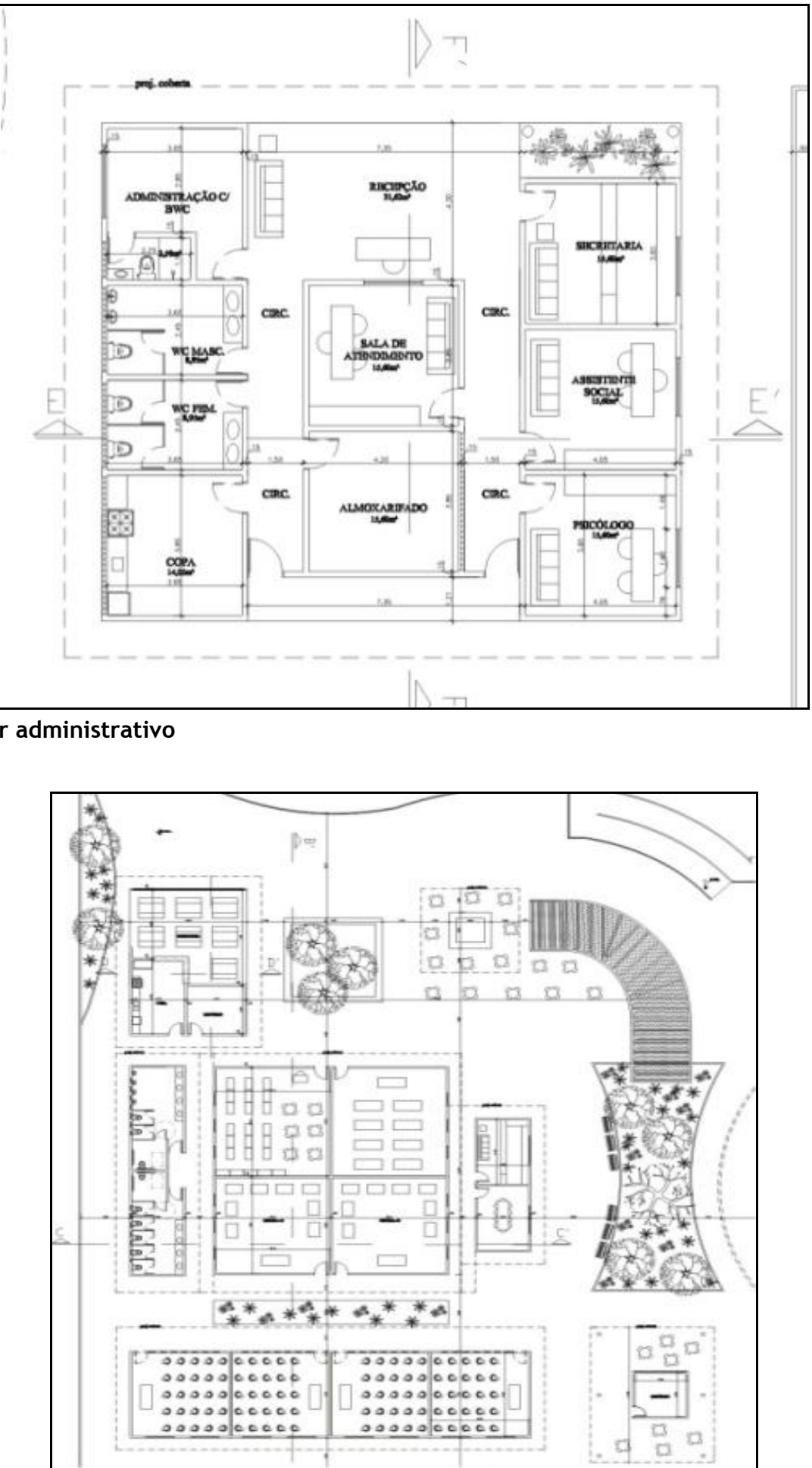

Figura 18 - Setor pedagógico 


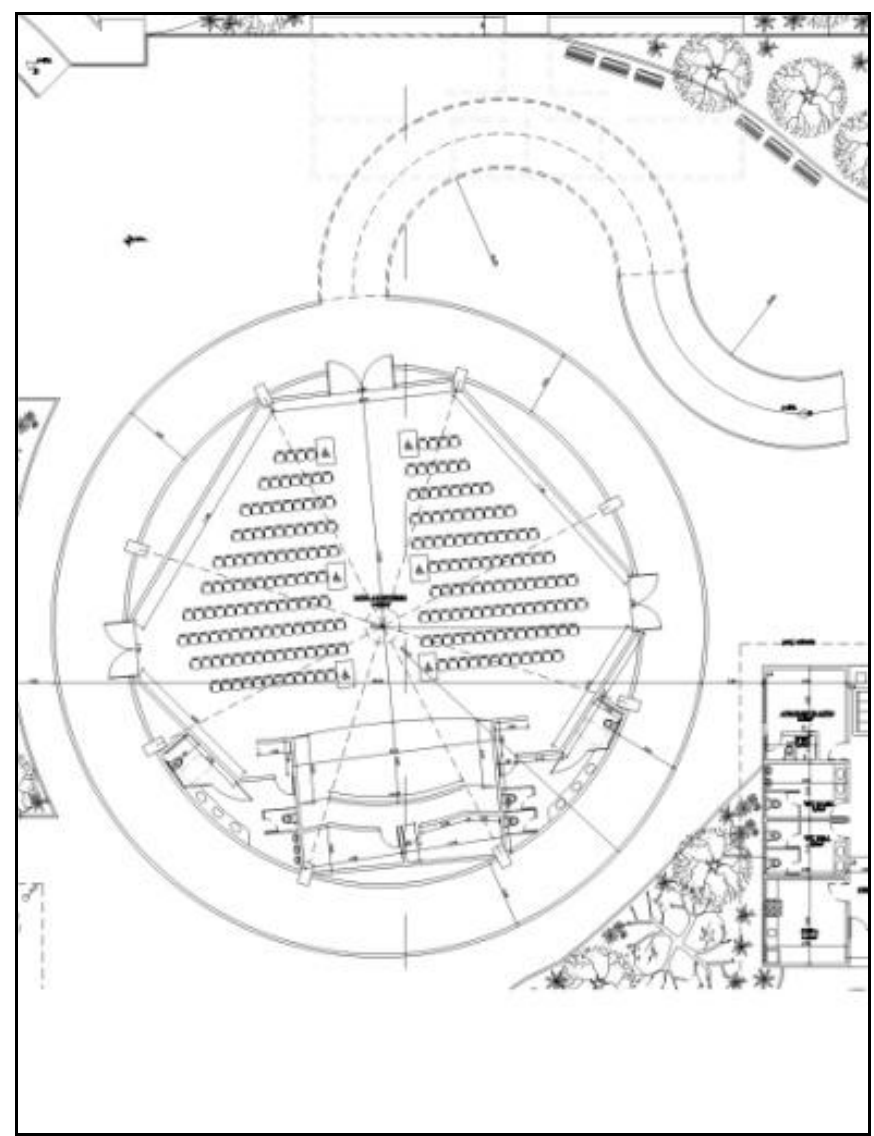

Figura 19 - Setor de lazer

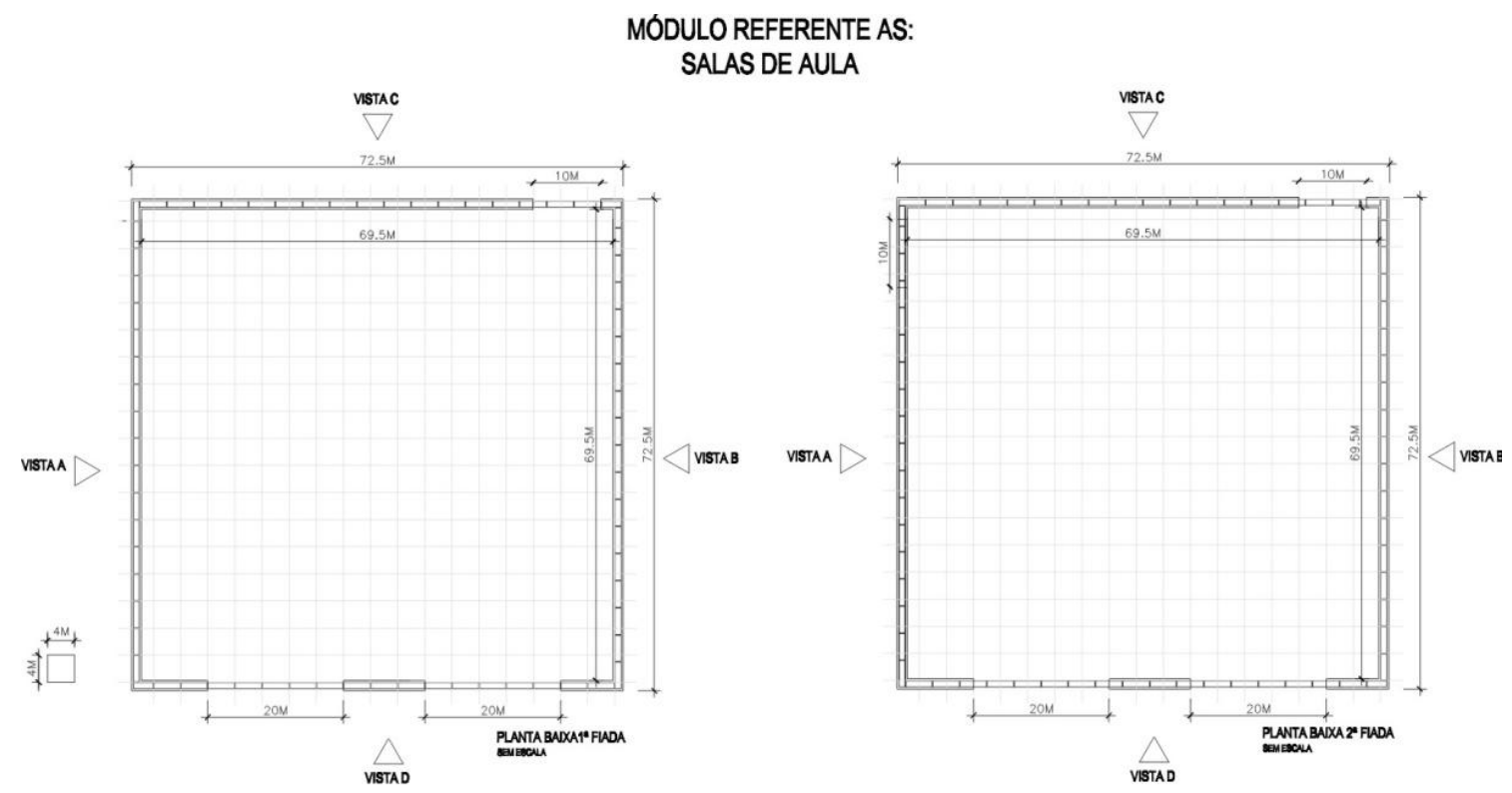

Figura 20 - Planta baixa, $1^{\mathrm{a}}$ e $2^{\mathrm{a}}$ fiada módulo base, sala de aula empregando malha $4 \mathrm{M} \times 4 \mathrm{M}$, alvenaria em blocos de concreto $39 \times 19 \times 9 \mathrm{~cm}$ 


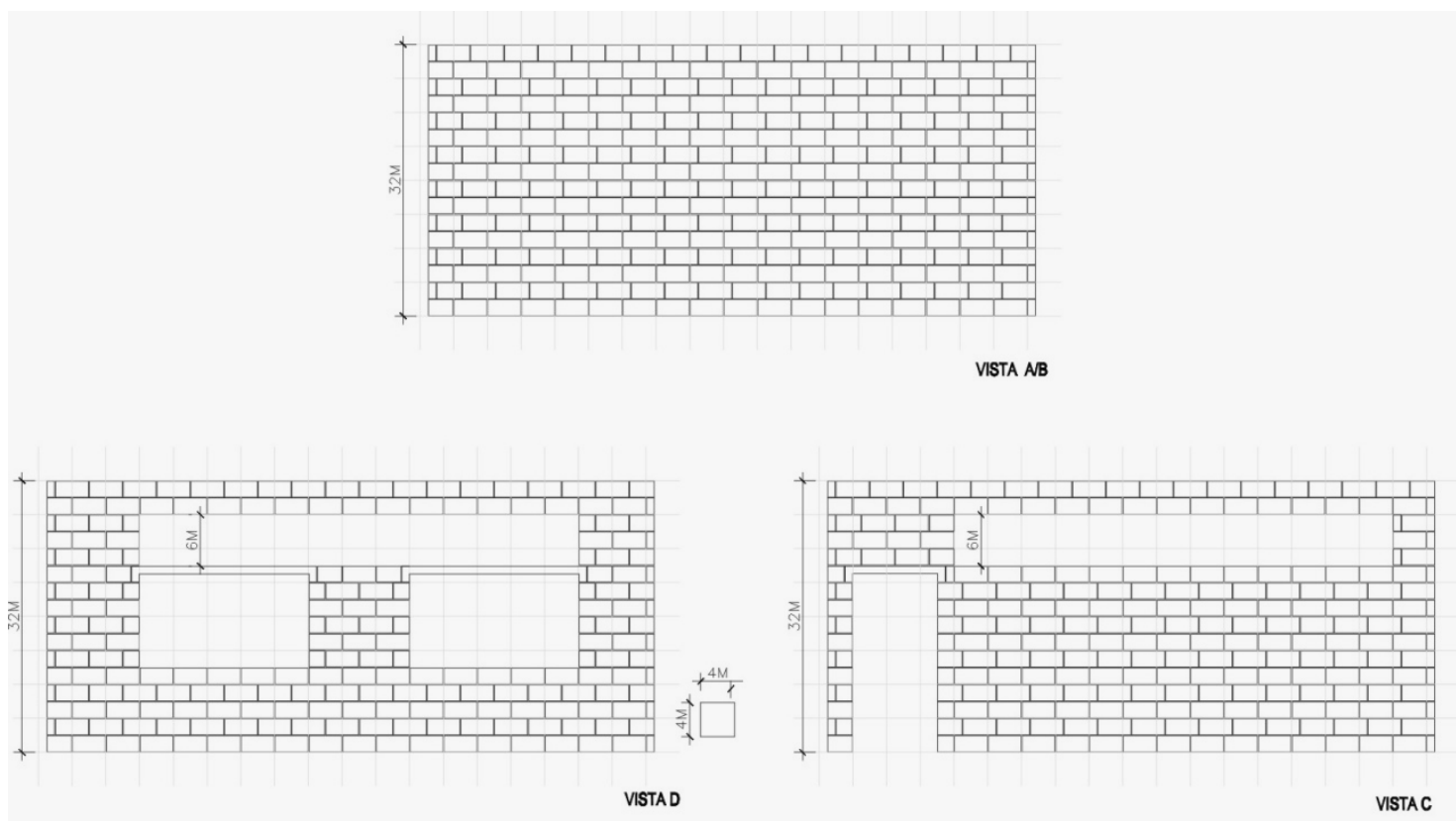

Figura 21 - Vistas dos painéis, sala de aula, empregando malha $4 \mathrm{M} \times 4 \mathrm{M}$, alvenaria em blocos de concreto $39 \times 19 \times 9 \mathrm{~cm}$

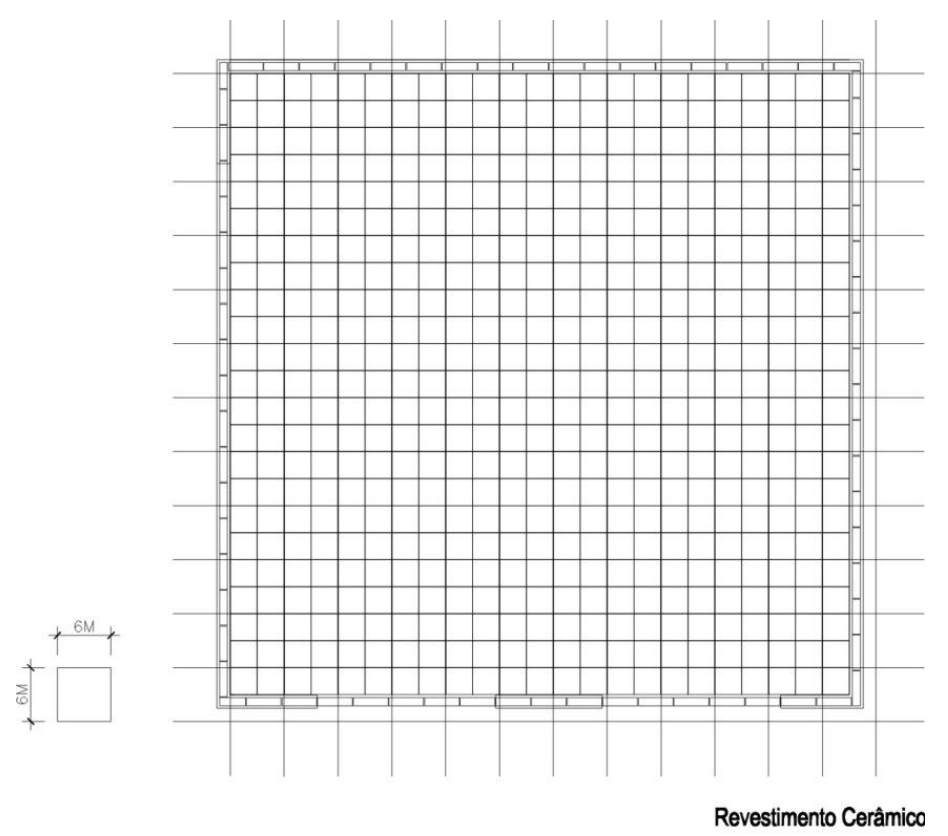

Figura 22 - Planta baixa, sala de aula, empregando malha $6 \mathrm{M} \times 6 \mathrm{M}$, revestimentos cerâmicos.

O setor de lazer buscou no emprego da forma de um de seus espaços mais ousadia, mostrando que a coordenação modular não só se apresentará em formas regulares, mas também em uma forma circular, constituída por blocos propostos com dimensões de 39x19x9 cm (ver Figura 23), cuja conexão é feita por meio de encaixes machofêmea. Um comparativo para a proposição das dimensões das peças foi realizado, pois, quanto maior fosse a proposta da dimensão da peça, mas desvantagens apareceriam na hora da execução, pois aumentariam os esforços devido ao peso das peças que seriam maiores, necessitando, assim, que houvesse um aumento nas seções dos pilares, além da questão ergonômica para os operários que fossem executar o serviço. A Tabela 1 apresenta uma síntese que justifica a escolha da dimensão da peça empregada. 
Tabela 1 - Síntese para o componente modular

\begin{tabular}{ccc}
\hline Bloco com área $=\mathbf{0 , 0 1 9 6} \mathbf{~ m}^{\mathbf{2}}$ & Volume das peças $\left(\mathbf{m}^{\mathbf{3}}\right)$ & Peso por peça $(\mathbf{k g})$ \\
\hline $\mathrm{c} / \mathrm{h}=0,19 \mathrm{~m}$ & 0,003724 & 0,00931 \\
$\mathrm{c} / \mathrm{h}=4,00 \mathrm{~m}$ & 0,0784 & 0,196 \\
\hline
\end{tabular}

Nota: *Peso específico do concreto armado $=2,50 \mathrm{~kg} / \mathrm{m}^{3}$
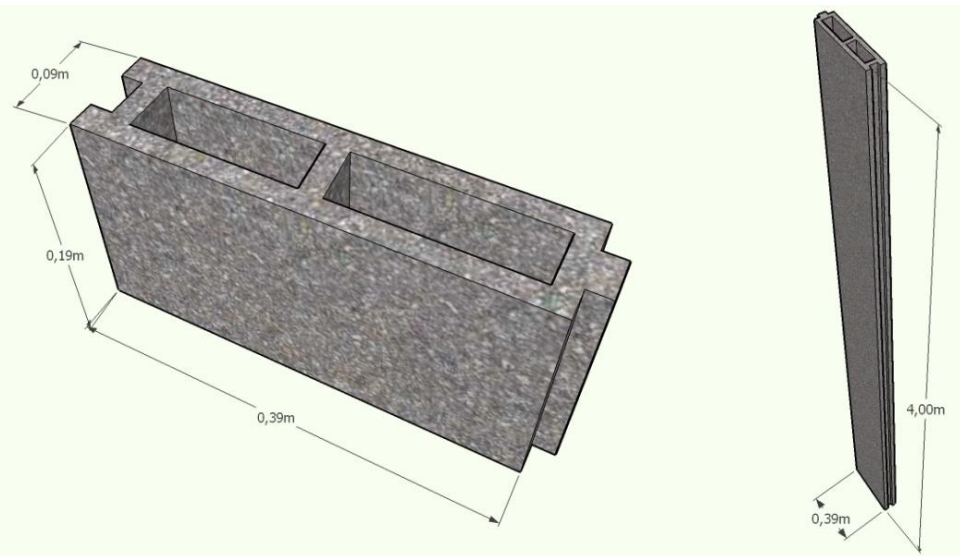

Figura 23 - Bloco proposto nas dimensões 39x19x9 cm, com encaixe macho-fêmea, empregado no setor de lazer

\section{Considerações finais e conclusões}

Nos padrões atuais, sustentabilidade, racionalização e redução de custos são questões bastante discutidas no âmbito da construção civil. Considerando esse contexto, acredita-se que a técnica da coordenação modular, associada a um esquema simples de pré-fabricação, pode melhorar significativamente a produtividade e a qualidade dos produtos.

A coordenação modular passa também a ser uma alternativa na busca pelos índices de qualidade, uma vez que atua diretamente nos componentes de um sistema construtivo, sejam eles mão de obra ou modulação prévia das dimensões ainda em projeto, compatibilizando-os de forma integrada.

No que se refere à alvenaria, a modulação objetiva acertar suas dimensões em planta associada também ao pé-direito da edificação, em função das dimensões dos componentes, de modo a não necessitar, ou pelo menos reduzir, cortes ou ajustes necessários a sua execução.

A alvenaria de blocos é formada, principalmente, pela associação dos componentes bloco, argamassa de assentamento dos blocos e argamassa de revestimento. Muitos fatores interferem na qualidade final da alvenaria acabada, tais como a regularidade geométrica da estrutura, a escolha dos blocos de vedação, as argamassas utilizadas para assentamento dos blocos e revestimento, além da mão de obra para a execução dos serviços (NASCIMENTO, 2007).

O mercado de Maceió disponibiliza para alvenaria de vedação tanto os blocos cerâmicos quanto os de concreto. Entretanto, o que se percebe é que em várias situações não são considerados aspectos importantes, como:

(a) dimensões, desvios de forma e peso de cada bloco, o que influencia na produtividade; e

(b) regularidade geométrica, que conduz a um assentamento mais uniforme, com economia de argamassa de assentamento e revestimento.

A racionalização construtiva pode ser entendida como a aplicação mais eficiente dos recursos em todas as atividades desenvolvidas para a construção da edificação. Quando se pretende implantar conceitos de racionalização da construção, deve-se iniciar pela estrutura da edificação. Em seguida, deve-se priorizar a alvenaria de vedação. Isso porque o subsistema de vedação vertical interfere nos demais subsistemas da edificação: revestimento, impermeabilização, esquadrias, instalações elétricas e de comunicação, instalações hidrossanitárias, etc. Todos esses serviços somados representam uma parcela considerável do custo de uma obra.

Em contraponto à alvenaria tradicional, a alvenaria dita racionalizada, mediante o uso da coordenação modular, apresenta as seguintes características: 
(a) utilização de blocos de melhor qualidade, preferencialmente com furos na vertical para facilitar a passagem de instalações;

(b) planejamento prévio;

(c) projeto da produção;

(d) treinamento da mão de obra;

(e) utilização de família de blocos com blocos compensadores para evitar a quebra de blocos na execução;

(f) redução do desperdício de materiais; e

(g) melhoria nas condições de limpeza e organização do canteiro de obras.

Dessa forma, conclui-se que a técnica da coordenação modular se estabelece como uma diretiva de projeto por exigir uma visualização integrada dos componentes do sistema construtivo ainda no momento de concepção. Essa adoção na fase de projeto contribui para eliminação das adaptações no canteiro, principais fontes de desperdícios e redução da produtividade. Além disso, explicita para os fabricantes a necessidade de produção de novos componentes, assim como ajustes nos já existentes, podendo, com isso, gerar um novo espaço de mercado. Num trabalho futuro será avaliada, ainda, a conectividade com sistemas de instalações.

\section{Referências bibliográficas}

\section{ASSOCIAÇÃO BRASILEIRA DE NORMAS TÉCNICAS. NBR ISO 9001: sistemas de gestão de ualidade: requisitos. Rio de Janeiro, 2008.}

BARBOZA, A. S. R. B. et al. Coordenação Modular e Conectividade Aplicada à Alvenaria de Blocos em Alternativas Tipológicas de Habitação de Interesse Social no Nordeste do Brasil. In: ENCONTRO NACIONAL DE TECNOLOGIA DO AMBIENTE CONSTRUÍDO, 12., 2008. Fortaleza. Anais... Fortaleza: Antac, 2008. 1 CDROM.
GREVEN, H. A.; BALDAUF, A. S. F. Introdução à Coordenação Modular da Construção no Brasil: uma abordagem atualizada. Porto Alegre: ANTAC, 2007. (Coleção Habitare, 9).

HABRAKEN, N. J. El Diseño de Soportes. Barcelona: Ed. Gustavo Gili, 1979.

NASCIMENTO, G. L. F. Caracterização dos Blocos Cerâmicos Comercializados em Maceió com Vistas a Aplicação da Coordenação Modular na Alvenaria de Vedação. 114 f. 2007. Maceió. Monografia (Trabalho de Conclusão de Curso em Engenharia Civil) - Centro de Tecnologia, Universidade Federal de Alagoas, Maceió, 2007.

NISSEN, H. Industrialized Building and Modular Design. London: Cement and Concrete Association, 1972.

WINTER, A. C. Diretrizes para Implantação de Sistemas Construtivos Abertos na Habitação de Interesse Social Através da Modulação. 2005. Curitiba, 150 f. Dissertação (Mestrado em Engenharia Civil) - Escola de Engenharia, Universidade Federal do Paraná, Curitiba, 2005.

\section{Agradecimentos}

Os autores agradecem especialmente à Financiadora de Estudos e Projetos (FINEP) pelo financiamento da pesquisa, às empresas participantes do levantamento de dados e ao Sindicato das Indústrias Cerâmicas do Estado de Alagoas, pelo apoio no desenvolvimento de toda a pesquisa.

\section{Revista Ambiente Construído}

Associação Nacional de Tecnologia do Ambiente Construído

Av. Osvaldo Aranha, $99-3^{\circ}$ andar, Centro

Porto Alegre - RS - Brasil

CEP 90035-190

Telefone: +55 (51) 3308-4084

Fax: +55 (51) 3308-4054

www.seer.ufrgs.br/ambienteconstruido

E-mail: ambienteconstruido@ufrgs.br 